\title{
Fixed points of generalized contractive mappings of integral type
}

\author{
Hamed H Alsulami ${ }^{1 *}$, Erdal Karapınar ${ }^{1,2}$, Donal O'Regan ${ }^{1,3}$ and Priya Shahi ${ }^{4}$
}

*Correspondence:
hamed9@hotmail.com;
hhaalsalmi@kau.edu.sa
${ }^{1}$ Nonlinear Analysis and Applied
Mathematics Research Group
(NAAM), King Abdulaziz University,
Jeddah, Saudi Arabia
Full list of author information is
available at the end of the article

available at the end of the article

\begin{abstract}
The aim of this paper is to introduce classes of $\alpha$-admissible generalized contractive type mappings of integral type and to discuss the existence of fixed points for these mappings in complete metric spaces. Our results improve and generalize fixed point results in the literature.

MSC: $46 \mathrm{~T} 99 ; 54 \mathrm{H} 25 ; 47 \mathrm{H} 10 ; 54 \mathrm{E} 50$

Keywords: $\alpha$-admissible mapping; fixed point; complete metric space; contractive mapping; partial order
\end{abstract}

\section{Introduction and preliminaries}

In 2002, Branciari [1] established a fixed point theorem for a single-valued mapping satisfying a contractive inequality of integral type; we also refer the reader to [2-10]. Recently, Liu et al. [11] (see also [12,13]) obtained fixed point theorems for general classes of contractive mappings of integral type in complete metric spaces. In this paper, using auxiliary functions, we establish some fixed point theorems for self-mappings satisfying a certain contractive inequality of integral type.

Throughout the paper $\mathbb{R}^{+}=[0,+\infty), \mathbb{N}_{0}=\mathbb{N} \cup\{0\}$, where $\mathbb{N}$ denotes the set of all positive integers, $(X, d)$ is a metric space and $f: X \rightarrow X$ is a self-mapping. Let

$\Phi_{1}=\left\{\varphi: \varphi: \mathbb{R}^{+} \rightarrow \mathbb{R}^{+}\right.$is Lebesgue integrable, summable on each compact subset of

$\mathbb{R}^{+}$and $\int_{0}^{\epsilon} \varphi(t) d t>0$ for each $\left.\epsilon>0\right\}$;

$\Phi_{2}=\left\{\varphi: \varphi: \mathbb{R}^{+} \rightarrow \mathbb{R}^{+}\right.$satisfies that $\liminf _{n \rightarrow \infty} \varphi\left(a_{n}\right)>0 \Leftrightarrow \liminf _{n \rightarrow \infty} a_{n}>0$ for each $\left.\left\{a_{n}\right\}_{n \in \mathbb{N}} \subset \mathbb{R}^{+}\right\}$

$\Phi_{3}=\left\{\varphi: \varphi: \mathbb{R}^{+} \rightarrow \mathbb{R}^{+}\right.$is nondecreasing continuous and $\left.\varphi(t)=0 \Leftrightarrow t=0\right\} ;$

$\Phi_{4}=\left\{\varphi: \varphi: \mathbb{R}^{+} \rightarrow \mathbb{R}^{+}\right.$satisfies that $\left.\varphi(0)=0\right\}$;

$\Phi_{5}=\left\{\varphi: \varphi: \mathbb{R}^{+} \rightarrow \mathbb{R}^{+}\right.$satisfies that $\lim _{\sup _{s \rightarrow t}} \varphi(s)<1$ for each $\left.t>0\right\} ;$

$\Phi_{6}=\left\{(\alpha, \beta): \alpha, \beta: \mathbb{R}^{+} \rightarrow[0,1)\right.$ satisfy that $\lim _{\sup } \sin _{s \rightarrow 0^{+}} \beta(s)<1, \lim \sup _{s \rightarrow t^{+}} \frac{\alpha(s)}{1-\beta(s)}<1$ and $\alpha(t)+\beta(t)<1$ for each $t>0\}$.

In 2013, Liu et al. [11] introduced the following three contractive mappings of integral type:

$$
\psi\left(\int_{0}^{d\left(f x_{2} f y\right)} \varphi(t) d t\right) \leq \psi\left(\int_{0}^{d(x, y)} \varphi(t) d t\right)-\phi\left(\int_{0}^{d(x, y)} \varphi(t) d t\right),
$$

(02014 Alsulami et al.; licensee Springer. This is an Open Access article distributed under the terms of the Creative Commons Attribution License (http://creativecommons.org/licenses/by/2.0), which permits unrestricted use, distribution, and reproduction in any medium, provided the original work is properly cited. 
where $(\varphi, \phi, \psi) \in \Phi_{1} \times \Phi_{2} \times \Phi_{3}$

$$
\psi\left(\int_{0}^{d(f x, f y)} \varphi(t) d t\right) \leq \alpha(d(x, y)) \psi\left(\int_{0}^{d(x, y)} \varphi(t) d t\right), \quad \forall x, y \in X
$$

where $(\varphi, \psi, \alpha) \in \Phi_{1} \times \Phi_{3} \times \Phi_{5}$, and

$$
\begin{aligned}
\psi\left(\int_{0}^{d(f x, f y)} \varphi(t) d t\right) \leq & \alpha(d(x, y)) \phi\left(\int_{0}^{d(x, f x)} \varphi(t) d t\right) \\
& +\beta(d(x, y)) \psi\left(\int_{0}^{d(y, f y)} \varphi(t) d t\right), \quad \forall x, y \in X,
\end{aligned}
$$

where $(\varphi, \psi, \phi) \in \Phi_{1} \times \Phi_{3} \times \Phi_{4}$ and $(\alpha, \beta) \in \Phi_{6}$.

The following lemmas will be used in the proof of our main results.

Lemma 1.1 [11] Let $\varphi \in \Phi_{1}$ and $\left\{r_{n}\right\}_{n \in \mathbb{N}}$ be a nonnegative sequence with $\lim _{n \rightarrow \infty} r_{n}=a$. Then we have

$$
\lim _{n \rightarrow \infty} \int_{0}^{r_{n}} \varphi(t) d t=\int_{0}^{a} \varphi(t) d t
$$

Lemma 1.2 [11] Let $\varphi \in \Phi_{1}$ and $\left\{r_{n}\right\}_{n \in \mathbb{N}}$ be a nonnegative sequence. Then we have the following equivalence:

$$
\lim _{n \rightarrow \infty} \int_{0}^{r_{n}} \varphi(t) d t=0
$$

if and only if $\lim _{n \rightarrow \infty} r_{n}=0$.

Lemma 1.3 [11] Let $\varphi \in \Phi_{2}$. Then $\varphi(t)>0$ if and only if $t>0$.

The notion of $\alpha$-admissibility was defined in [14] and appreciated by several authors [15-17] (see also [18-31]).

Definition 1.1 [14] Let $T: X \rightarrow X$ and $\alpha: X \times X \rightarrow[0, \infty)$. The mapping $T$ is said to be $\alpha$-admissible if for all $x, y \in X$, we have

$$
\alpha(x, y) \geq 1 \quad \Rightarrow \quad \alpha(T x, T y) \geq 1
$$

Definition 1.2 Let $T: X \rightarrow X$ and $\alpha: X \times X \rightarrow[0, \infty)$. The mapping $T$ is said to be weak triangular $\alpha$-admissible if for all $x \in X$ we have

$$
\alpha(x, T x) \geq 1 \quad \text { and } \quad \alpha\left(T x, T^{2} x\right) \geq 1 \quad \Rightarrow \quad \alpha\left(x, T^{2} x\right) \geq 1 .
$$

\section{Main results}

In this section, we state and prove our main results. We start with the following general contractive inequality of integral type. 
Definition 2.1 Let $(X, d)$ be a complete metric space, $f: X \rightarrow X$ and $\alpha: X \times X \rightarrow[0, \infty)$ be mappings. Suppose that there exist $(\varphi, \phi, \psi) \in \Phi_{1} \times \Phi_{2} \times \Phi_{3}$ and $L \geq 0$ such that

$$
\begin{aligned}
\alpha(x, y) \psi\left(\int_{0}^{d(f x, f y)} \varphi(t) d t\right) \leq & \psi\left(\int_{0}^{M(x, y)} \varphi(t) d t\right)-\phi\left(\int_{0}^{N(x, y)} \varphi(t) d t\right) \\
& +L \psi\left(\int_{0}^{O(x, y)} \varphi(t) d t\right)
\end{aligned}
$$

for all $x, y \in X$, where

$$
M(x, y)=\max \left\{d(x, y), d(x, f x), d(y, f y), \frac{1}{2}[d(x, f y)+d(y, f x)]\right\},
$$

and

$$
N(x, y)=\max \{d(x, y), d(x, f x), d(y, f y)\}
$$

and

$$
O(x, y)=\min \{d(x, f x), d(y, f y), d(y, f x), d(x, f y)\} .
$$

Then $f$ is said to be an $\alpha$-admissible contractive inequality of integral type $I$.

Theorem 2.1 Let $(X, d)$ be a complete metric space. Suppose that $f: X \rightarrow X$ is an $\alpha$ admissible contractive inequality of integral type I which satisfies

(i) $f$ is weak triangular $\alpha$-admissible;

(ii) there exists $x \in X$ such that either $\alpha(x, f x) \geq 1$ or $\alpha(f x, x) \geq 1$;

(iii) $f$ is continuous.

Then $T$ has a fixed point.

Proof From (ii), there exists a point $x \in X$ such that $\alpha(x, f x) \geq 1$ (due to the symmetry of the metric, the other case yields the same result). Let $x_{0}=x$ and we define an iterative sequence $\left\{x_{n}\right\}$ in $X$ by $x_{n+1}=f x_{n}$ for all $n \geq 0$. Note that we have

$$
\alpha\left(x_{0}, x_{1}\right)=\alpha\left(x_{0}, f x_{0}\right) \geq 1 \quad \Rightarrow \quad \alpha\left(f x_{0}, f x_{1}\right)=\alpha\left(x_{1}, x_{2}\right) \geq 1 .
$$

Inductively, we have

$$
\alpha\left(x_{n}, x_{n+1}\right) \geq 1 \quad \text { for all } n \in \mathbb{N}_{0} .
$$

In the sequel, we use the following abbreviations:

$$
d_{n}=d\left(x_{n}, x_{n+1}\right) \quad \text { and } \quad \alpha_{n}=\alpha\left(x_{n}, x_{n+1}\right) \quad \text { for } n \in \mathbb{N}_{0} .
$$

Notice that if $x_{n_{0}}=x_{n_{0}+1}$ for some $n_{0}$, then it is evident that $u=x_{n_{0}}$ is a fixed point of $f$. This completes the proof. Consequently, we assume that $x_{n} \neq x_{n+1}$ for all $n \in \mathbb{N}_{0}$, that is,

$$
0<d_{n}=d\left(x_{n}, x_{n+1}\right) \quad \text { for all } n \in \mathbb{N}_{0} .
$$


We now prove that $\left\{d_{n}\right\}$ is a non-increasing sequence of real numbers, that is,

$$
d_{n} \leq d_{n-1}, \quad \forall n \in \mathbb{N} .
$$

Suppose, on the contrary, that inequality (10) does not hold. Thus, there exists some $n_{0} \in \mathbb{N}$ such that

$$
d_{n_{0}}>d_{n_{0}-1}
$$

From (9) and (11), we get

$$
0<\int_{0}^{d_{n_{0}-1}} \varphi(t) d t<\int_{0}^{d_{n_{0}}} \varphi(t) d t
$$

Regarding again (9) and (11) together with the properties of $\psi$, we conclude that

$$
0=\psi(0)<\psi\left(\int_{0}^{d_{n_{0}-1}} \varphi(t) d t\right) \leq \psi\left(\int_{0}^{d_{n_{0}}} \varphi(t) d t\right)
$$

Using equations (13), (7), (6), (8) and the fact that $(\varphi, \phi, \psi) \in \Phi_{1} \times \Phi_{2} \times \Phi_{3}$, we obtain immediately that

$$
\begin{aligned}
\psi\left(\int_{0}^{d_{n_{0}-1}} \varphi(t) d t\right) \leq & \psi\left(\int_{0}^{d_{n_{0}}} \varphi(t) d t\right) \\
\leq & \alpha_{n_{0}} \psi\left(\int_{0}^{d_{n_{0}}} \varphi(t) d t\right)=\alpha_{n_{0}} \psi\left(\int_{0}^{d\left(f^{n_{0}} x f^{n_{0}+1} x\right)} \varphi(t) d t\right) \\
\leq & \psi\left(\int_{0}^{M\left(f^{n_{0}-1} x, f^{n_{0}} x\right)} \varphi(t) d t\right)-\phi\left(\int_{0}^{N\left(f^{n_{0}-1} x f^{n_{0}} x\right)} \varphi(t) d t\right) \\
& +L \psi\left(\int_{0}^{O\left(f^{n_{0}-1} x, f^{\left.n_{0} x\right)}\right.} \varphi(t) d t\right),
\end{aligned}
$$

where

$$
\begin{aligned}
M\left(f^{n_{0}-1} x, f^{n_{0}} x\right) \leq & \max \left\{d\left(f^{n_{0}-1} x, f^{n_{0}} x\right), d\left(f^{n_{0}} x, f^{n_{0}+1} x\right)\right\}=\max \left\{d_{n_{0}-1}, d_{n_{0}}\right\}, \\
N\left(f^{n_{0}-1} x, f^{n_{0}} x\right)= & \max \left\{d\left(f^{n_{0}-1} x, f^{n_{0}} x\right), d\left(f^{n_{0}} x, f^{n_{0}+1} x\right)\right\}=\max \left\{d_{n_{0}-1}, d_{n_{0}}\right\}, \\
O\left(f^{n_{0}-1} x, f^{n_{0}} x\right)= & \min \left\{d\left(f^{n_{0}-1} x, f^{n_{0}} x\right), d\left(f^{n_{0}} x, f^{n_{0}+1} x\right),\right. \\
& \left.d\left(f^{n_{0}} x, f^{n_{0}} x\right), d\left(f^{n_{0}-1} x, f^{n_{0}+1} x\right)\right\}=0 .
\end{aligned}
$$

Thus $M\left(f^{n_{0}-1} x, f^{n_{0}} x\right) \leq d_{n_{0}}$ and $N\left(f^{n_{0}-1} x, f^{n_{0}} x\right)=d_{n_{0}}$ from (11). Hence, inequality (14) turns into

$$
\begin{aligned}
\psi\left(\int_{0}^{d_{n_{0}}} \varphi(t) d t\right) & \leq \alpha_{n_{0}} \psi\left(\int_{0}^{d_{n_{0}}} \varphi(t) d t\right) \\
& \leq \psi\left(\int_{0}^{d_{n_{0}}} \varphi(t) d t\right)-\phi\left(\int_{0}^{d_{n_{0}}} \varphi(t) d t\right)<\psi\left(\int_{0}^{d_{n_{0}}} \varphi(t) d t\right),
\end{aligned}
$$


which is a contradiction. Hence (10) holds. Thus, there exists a constant $c \geq 0$ such that $\lim _{n \rightarrow \infty} d_{n}=c \geq 0$.

Next we show that $c=0$, that is,

$$
\lim _{n \rightarrow \infty} d_{n}=0
$$

Suppose, on the contrary, that $c>0$. It follows from (6) and (7) that

$$
\begin{aligned}
\psi\left(\int_{0}^{d_{n}} \varphi(t) d t\right)= & \psi\left(\int_{0}^{d\left(f^{n} x, f^{n+1} x\right)} \varphi(t) d t\right) \\
\leq & \alpha\left(x_{n}, x_{n+1}\right) \psi\left(\int_{0}^{d\left(f^{n} x, f^{n+1} x\right)} \varphi(t) d t\right) \\
\leq & \psi\left(\int_{0}^{M\left(f^{n-1} x_{f} f^{n} x\right)} \varphi(t) d t\right)-\phi\left(\int_{0}^{N\left(f^{n-1} x_{f} f^{n} x\right)} \varphi(t) d t\right) \\
& +L \psi\left(\int_{0}^{O\left(f^{n-1} x_{f} f^{n} x\right)} \varphi(t) d t\right),
\end{aligned}
$$

where

$$
\begin{aligned}
& M\left(f^{n-1}, f^{n} x\right) \leq \max \left\{d\left(f^{n-1} x, f^{n} x\right), d\left(f^{n} x, f^{n+1} x\right)\right\}=\max \left\{d_{n-1}, d_{n}\right\}, \\
& N\left(f^{n-1} x, f^{n} x\right)=\max \left\{d\left(f^{n-1} x, f^{n} x\right), d\left(f^{n} x, f^{n+1} x\right)\right\}=\max \left\{d_{n-1}, d_{n}\right\}, \\
& O\left(f^{n-1} x, f^{n} x\right)=\min \left\{d\left(f^{n-1} x, f^{n} x\right), d\left(f^{n} x, f^{n+1} x\right), d\left(f^{n} x, f^{n} x\right), d\left(f^{n-1} x, f^{n+1} x\right)\right\}=0 .
\end{aligned}
$$

Hence, inequality (17) becomes

$$
\begin{aligned}
\psi\left(\int_{0}^{d_{n}} \varphi(t) d t\right) & =\psi\left(\int_{0}^{d\left(f^{n} x_{f} f^{n+1} x\right)} \varphi(t) d t\right) \leq \alpha_{n} \psi\left(\int_{0}^{d\left(f^{n} x_{f} f^{n+1} x\right)} \varphi(t) d t\right) \\
& \leq \psi\left(\int_{0}^{d_{n-1}} \varphi(t) d t\right)-\phi\left(\int_{0}^{d_{n-1}} \varphi(t) d t\right) .
\end{aligned}
$$

Taking the upper limit in (18) and using Lemma 1.1 and noting $(\varphi, \phi, \psi) \in \Phi_{1} \times \Phi_{2} \times \Phi_{3}$, we get

$$
\begin{aligned}
\psi\left(\int_{0}^{c} \varphi(t) d t\right) & =\lim _{n \rightarrow \infty} \sup \psi\left(\int_{0}^{d_{n}} \varphi(t) d t\right) \\
& \leq \lim _{n \rightarrow \infty} \sup \left[\psi\left(\int_{0}^{d_{n-1}} \varphi(t) d t\right)-\phi\left(\int_{0}^{d_{n-1}} \varphi(t) d t\right)\right] \\
& =\psi\left(\int_{0}^{c} \varphi(t) d t\right)-\lim _{n \rightarrow \infty} \inf \phi\left(\int_{0}^{d_{n-1}} \varphi(t) d t\right) \\
& <\psi\left(\int_{0}^{c} \varphi(t) d t\right)
\end{aligned}
$$

which is a contradiction. Hence $c=0$. 
Next we prove that $\left\{f^{n} x\right\}_{n \in \mathbb{N}}$ is a Cauchy sequence. Suppose, on the contrary, that $\left\{f^{n} x\right\}_{n \in \mathbb{N}}$ is not a Cauchy sequence. Thus, there is a constant $\epsilon>0$ such that for each positive integer $k$, there are positive integers $m(k)$ and $n(k)$ with $m(k)>n(k)>k$ satisfying

$$
d\left(f^{m(k)} x, f^{n(k)} x\right)>\epsilon .
$$

For each positive integer $k$, let $m(k)$ denote the least integer exceeding $n(k)$ and satisfying (20). This implies that

$$
d\left(f^{m(k)} x, f^{n(k)} x\right)>\epsilon \quad \text { and } \quad d\left(f^{m(k)-1} x, f^{n(k)} x\right) \leq \epsilon \quad \text { for all } k \in \mathbb{N} .
$$

On the other hand, we have

$$
\begin{aligned}
& d\left(f^{m(k)} x, f^{n(k)} x\right) \leq d\left(f^{n(k)} x, f^{m(k)-1} x\right)+d_{m(k)-1}, \quad \forall k \in \mathbb{N}, \\
& \left|d\left(f^{m(k)} x, f^{n(k)+1} x\right)-d\left(f^{m(k)} x, f^{n(k)} x\right)\right| \leq d_{n(k)}, \quad \forall k \in \mathbb{N}, \\
& \left|d\left(f^{m(k)+1} x, f^{n(k)+1} x\right)-d\left(f^{m(k)} x, f^{n(k)+1} x\right)\right| \leq d_{m(k)}, \quad \forall k \in \mathbb{N}, \\
& \left|d\left(f^{m(k)+1} x, f^{n(k)+1} x\right)-d\left(f^{m(k)+1} x, f^{n(k)+2} x\right)\right| \leq d_{n(k)+1}, \quad \forall k \in \mathbb{N} .
\end{aligned}
$$

In view of (21) and (22), we infer that

$$
\begin{aligned}
& \lim _{k \rightarrow \infty} d\left(f^{n(k)} x, f^{m(k)} x\right)=\epsilon, \\
& \lim _{k \rightarrow \infty} d\left(f^{m(k)} x, f^{n(k)+1} x\right)=\epsilon, \\
& \lim _{k \rightarrow \infty} d\left(f^{m(k)+1} x, f^{n(k)+1} x\right)=\epsilon, \\
& \lim _{k \rightarrow \infty} d\left(f^{m(k)+1} x, f^{n(k)+2} x\right)=\epsilon .
\end{aligned}
$$

Using the weak triangular alpha admissible property of $f$, we get in view of (7)

$$
\alpha\left(f^{m(k)} x, f^{n(k)+1} x\right) \geq 1 .
$$

From (6) and (24), we have

$$
\begin{aligned}
& \psi\left(\int_{0}^{d\left(f^{m(k)+1} x f^{n(k)+2} x\right)} \varphi(t) d t\right) \\
& \quad \leq \alpha\left(f^{m(k)} x, f^{n(k)+1} x\right) \psi\left(\int_{0}^{d\left(f^{m(k)+1} x f^{n(k)+2} x\right)} \varphi(t) d t\right) \\
& \quad \leq \psi\left(\int_{0}^{M\left(f^{m(k)} x f^{n(k)+1}\right)} \varphi(t) d t\right)-\phi\left(\int_{0}^{N\left(f^{m(k)} x, f^{n(k)+1}\right)} \varphi(t) d t\right) \\
& \quad+L \psi\left(\int_{0}^{O\left(f^{m(k)} x f^{n(k)+1}\right)} \varphi(t) d t\right), \quad \forall k \in \mathbb{N} .
\end{aligned}
$$


Taking the upper limit in (25) and using (23), $(\varphi, \phi, \psi) \in \Phi_{1} \times \Phi_{2} \times \Phi_{3}$ and Lemma 1.1, we get

$$
\begin{aligned}
& \psi\left(\int_{0}^{\epsilon} \varphi(t) d t\right)=\lim _{k \rightarrow \infty} \sup \psi\left(\int_{0}^{d\left(f^{m(k)+1} x_{f} n^{(k)+2} x\right)} \varphi(t) d t\right) \\
& \leq \limsup _{k \rightarrow \infty} \alpha\left(f^{m(k)} x, f^{n(k)+1} x\right) \psi\left(\int_{0}^{d\left(f^{m(k)+1} x_{x} f^{n(k)+2} x\right)} \varphi(t) d t\right) \\
& \leq \limsup _{k \rightarrow \infty} \psi\left(\int_{0}^{M\left(f^{m(k)} x_{i} f^{n(k)+1} x\right)} \varphi(t) d t\right) \\
& -\liminf _{k \rightarrow \infty} \phi\left(\int_{0}^{N\left(f^{m(k)} x_{x} f^{n(k)+1} x\right)} \varphi(t) d t\right) \\
& +L \limsup _{k \rightarrow \infty} \psi\left(\int_{0}^{O\left(f^{m(k)} x_{f} n^{n(k)+1}\right)} \varphi(t) d t\right) \\
& =\psi\left(\int_{0}^{\epsilon} \varphi(t) d t\right)-\liminf _{k \rightarrow \infty} \phi\left(\int_{0}^{d\left(f^{m(k)} x f^{n(k)+1} x\right)} \varphi(t) d t\right) \\
& +L \limsup _{k \rightarrow \infty} \psi\left(\int_{0}^{O\left(f^{m(k)} x_{f} f^{n(k)+1}\right)} \varphi(t) d t\right) \\
& =\psi\left(\int_{0}^{\epsilon} \varphi(t) d t\right)-\liminf _{k \rightarrow \infty} \phi\left(\int_{0}^{d\left(f^{m(k)} x f^{n(k)+1} x\right)} \varphi(t) d t\right) \\
& <\psi\left(\int_{0}^{\epsilon} \varphi(t) d t\right)
\end{aligned}
$$

which is impossible. Thus $\left\{f^{n} x\right\}_{n \in \mathbb{N}}$ is a Cauchy sequence. Now, since $(X, d)$ is complete, there exists a point $a \in X$ such that $\lim _{n \rightarrow \infty} f^{n} x=a$. From the continuity of $f$, it follows that $x_{n}=f x_{n+1} \rightarrow f a$ as $n \rightarrow+\infty$. From the uniqueness of limits, we get $a=f a$, that is, $a$ is a fixed point of $f$. This completes the proof.

Theorem 2.2 Let $(X, d)$ be a complete metric space. Suppose that $f: X \rightarrow X$ is an $\alpha$ admissible contractive inequality of integral type I which satisfies

(i) $f$ is weak triangular $\alpha$-admissible;

(ii) there exists $x \in X$ such that either $\alpha(x, f x) \geq 1$ or $\alpha(f x, x) \geq 1$;

(iii) if $\left\{x_{n}\right\}$ is a sequence in $X$ such that $\alpha\left(x_{n}, x_{n+1}\right) \geq 1$ for all $n$ and $x_{n} \rightarrow x \in X$ as $n \rightarrow+\infty$, then $\alpha\left(x_{n}, x\right) \geq 1$ for all $n$.

Then $f$ has a fixed point.

Proof Following the proof in Theorem 2.1, we see that $\left\{x_{n}\right\}$ is a Cauchy sequence in the complete metric space $(X, d)$. Then there exists $a \in X$ such that $x_{n} \rightarrow a$ as $n \rightarrow+\infty$. On the other hand, from inequality (7) and hypothesis (iii), we have

$$
\alpha\left(x_{n}, a\right) \geq 1 \quad \forall n \in \mathbb{N} .
$$


Let us suppose that $a \neq f a$. In view of the above inequality and (6), we obtain that

$$
\begin{aligned}
\psi\left(\int_{0}^{d\left(f^{n+1} x, f a\right)} \varphi(t) d t\right) \leq & \alpha\left(x_{n}, a\right) \psi\left(\int_{0}^{d\left(f^{n+1} x, f a\right)} \varphi(t) d t\right) \\
\leq & \psi\left(\int_{0}^{M\left(f^{n} x, a\right)} \varphi(t) d t\right)-\phi\left(\int_{0}^{N\left(f^{n} x, a\right)} \varphi(t) d t\right) \\
& +L \psi\left(\int_{0}^{O\left(f^{n} x, a\right)} \varphi(t) d t\right)
\end{aligned}
$$

for all $n \in \mathbb{N}$. On the other hand, we have

$$
\begin{aligned}
& M\left(f^{n} x, a\right)=\max \left\{d\left(f^{n} x, a\right), d\left(f^{n} x, f^{n+1} x\right), d(a, f a), \frac{1}{2}\left[d\left(f^{n} x, f a\right)+d\left(a, f^{n+1} x\right)\right]\right\}, \\
& N\left(f^{n} x, a\right)=\max \left\{d\left(f^{n} x, a\right), d\left(f^{n} x, f^{n+1} x\right), d(a, f a)\right\}, \\
& O\left(f^{n} x, a\right)=\min \left\{d\left(f^{n} x, f^{n+1} x\right), d(a, f a), d\left(f^{n} x, f a\right), d\left(a, f^{n+1} x\right)\right\} .
\end{aligned}
$$

Taking the upper limit in (27), in view of Lemmas 1.1 and 1.2 and $(\varphi, \phi, \psi) \in \Phi_{1} \times \Phi_{2} \times \Phi_{3}$, we infer from (28) that

$$
\begin{aligned}
\psi\left(\int_{0}^{d(a, f a)} \varphi(t) d t\right)= & \lim _{n \rightarrow \infty} \sup \psi\left(\int_{0}^{d\left(f^{n+1} x, f a\right)} \varphi(t) d t\right) \\
\leq & \lim _{n \rightarrow \infty} \sup \alpha\left(x_{n}, a\right) \psi\left(\int_{0}^{d\left(f^{n+1} x, f a\right)} \varphi(t) d t\right) \\
\leq & \lim _{n \rightarrow \infty} \sup \psi\left(\int_{0}^{M\left(f^{n} x, a\right)} \varphi(t) d t\right)-\lim _{n \rightarrow \infty} \inf \phi\left(\int_{0}^{N\left(f^{n} x, a\right)} \varphi(t) d t\right) \\
& +L \lim _{n \rightarrow \infty} \sup \psi\left(\int_{0}^{O\left(f^{n} x, a\right)} \varphi(t) d t\right) \\
\leq & \psi\left(\int_{0}^{d(a, f a)} \varphi(t) d t\right)-\phi\left(\int_{0}^{d(a, f a)} \varphi(t) d t\right) \\
< & \psi\left(\int_{0}^{d(a, f a)} \varphi(t) d t\right),
\end{aligned}
$$

which is a contradiction. Thus, we have $a=f a$.

Now, we present another contractive inequality of integral type.

Definition 2.2 Let $(X, d)$ be a complete metric space and $f: X \rightarrow X$ be a self-mapping. Suppose that there exist $(\varphi, \phi, \psi) \in \Phi_{1} \times \Phi_{2} \times \Phi_{3}$ and $L \geq 0$ such that

$$
\begin{aligned}
\alpha(x, y) \psi\left(\int_{0}^{d(f x, f y)} \varphi(t) d t\right) \leq & \psi\left(\int_{0}^{M^{*}(x, y)} \varphi(t) d t\right)-\phi\left(\int_{0}^{N^{*}(x, y)} \varphi(t) d t\right) \\
& +L \psi\left(\int_{0}^{O(x, y)} \varphi(t) d t\right)
\end{aligned}
$$


for all $x, y \in X$, where

$$
M^{*}(x, y)=\max \left\{d(x, y), \frac{1}{2}[d(x, f x)+d(y, f y)], \frac{1}{2}[d(x, f y)+d(y, f x)]\right\},
$$

and

$$
N^{*}(x, y)=\max \left\{d(x, y), \frac{1}{2}[d(x, f x)+d(y, f y)]\right\}
$$

and

$$
O(x, y)=\min \{d(x, f x), d(y, f y), d(y, f x), d(x, f y)\}
$$

Then $f$ is said to be an $\alpha$-admissible contractive inequality of integral type $I I$.

We omit the proof of the following two theorems since they mimic the proof of Theorem 2.1 and Theorem 2.2.

Theorem 2.3 Let $(X, d)$ be a complete metric space. Suppose that $f: X \rightarrow X$ is an $\alpha$ admissible contractive inequality of integral type II which satisfies

(i) $f$ is weak triangular $\alpha$-admissible;

(ii) there exists $x_{0} \in X$ such that either $\alpha\left(x_{0}, f x_{0}\right) \geq 1$ or $\alpha\left(f x_{0}, x_{0}\right) \geq 1$;

(iii) $f$ is continuous.

Then $T$ has a fixed point.

Theorem 2.4 Let $(X, d)$ be a complete metric space. Suppose that $f: X \rightarrow X$ is an $\alpha$ admissible contractive inequality of integral type II which satisfies

(i) $f$ is weak triangular $\alpha$-admissible;

(ii) there exists $x_{0} \in X$ such that either $\alpha\left(x_{0}, f x_{0}\right) \geq 1$ or $\alpha\left(f x_{0}, x_{0}\right) \geq 1$;

(iii) if $\left\{x_{n}\right\}$ is a sequence in $X$ such that $\alpha\left(x_{n}, x_{n+1}\right) \geq 1$ for all $n$ and $x_{n} \rightarrow x \in X$ as $n \rightarrow+\infty$, then $\alpha\left(x_{n}, x\right) \geq 1$ for all $n$.

Then $T$ has a fixed point.

The following condition provides the uniqueness of fixed points of the maps considered in Theorem 2.3 and Theorem 2.4. Consider

$\left(U^{*}\right)$ for all $x, y \in \operatorname{Fix}(f)$, there exists $z \in X$ such that $\alpha(x, z) \geq 1$ and $\alpha(y, z) \geq 1$, where $\operatorname{Fix}(f)$ denotes the set of fixed points of $f$.

Theorem 2.5 If the condition $\left(U^{*}\right)$ is added to the hypotheses of Theorem 2.3 (respectively, Theorem 2.4), then the fixed point $u$ of $T$ is unique.

Proof From $\left(U^{*}\right)$, we have

$$
\alpha(x, z) \geq 1 \quad \text { and } \quad \alpha(y, z) \geq 1 \text {. }
$$

Define the sequence $\left\{z_{n}\right\}$ in $X$ by $z_{n+1}=f z_{n}$ for all $n \geq 0$ and $z_{0}=z$. Using the weak triangular $\alpha$-admissible property of $f$, we infer that

$$
\alpha\left(x, z^{n}\right) \geq 1 \quad \text { and } \quad \alpha\left(y, z_{n}\right) \geq 1
$$


for all $n \in \mathbb{N}$. Using inequality (6), we get

$$
\begin{aligned}
\int_{0}^{d\left(x, z_{n}\right)} \varphi(t) d t & =\int_{0}^{d\left(f x, f\left(z_{n-1}\right)\right)} \varphi(t) d t \\
\leq & \alpha\left(x, z_{n-1}\right) \int_{0}^{d\left(f x_{x} f\left(z_{n-1}\right)\right)} \varphi(t) d t \\
\leq & \psi\left(\int_{0}^{d\left(x, z_{n-1}\right)} \varphi(t) d t\right)-\phi\left(\int_{0}^{d\left(x, z_{n-1}\right)} \varphi(t) d t\right) \\
& +L \psi\left(\int_{0}^{d\left(x, z_{n-1}\right)} \varphi(t) d t\right) .
\end{aligned}
$$

Using standard techniques, we derive that $d\left(x, z_{n}\right) \leq d\left(x, z_{n-1}\right)$ and hence the sequence $\left\{d\left(x, z_{n}\right)\right\}$ converges to some $L \geq 0$. If $L=0$, then the proof is complete. Indeed, we get that $z_{n} \rightarrow x$ and analogously, $z_{n} \rightarrow y$ as $n \rightarrow \infty$ and from the uniqueness of limits, we derive that $x=y$. Suppose, on the contrary, $L>0$. By letting $n \rightarrow \infty$, we derive from the above inequality that

$$
\int_{0}^{L} \varphi(t) d t \leq \psi\left(\int_{0}^{L} \varphi(t) d t\right)-\phi\left(\int_{0}^{L} \varphi(t) d t\right)
$$

which is a contradiction.

Now we introduce a third type of contractive inequality of integral type.

Definition 2.3 Let $(X, d)$ be a complete metric space and $f: X \rightarrow X$ be a self-mapping. Suppose that there exist $(\varphi, \phi, \psi) \in \Phi_{1} \times \Phi_{2} \times \Phi_{3}$ such that

$$
\alpha(x, y) \psi\left(\int_{0}^{d\left(f x_{2} f y\right)} \varphi(t) d t\right) \leq \psi\left(\int_{0}^{d(x, y)} \varphi(t) d t\right)-\phi\left(\int_{0}^{d(x, y)} \varphi(t) d t\right) .
$$

Then $f$ is said to be an $\alpha$-admissible contractive inequality of integral type III.

Theorem 2.6 Let $(X, d)$ be a complete metric space. Suppose that $f: X \rightarrow X$ is an $\alpha$ admissible contractive inequality of integral type III which satisfies

(i) $f$ is weak triangular $\alpha$-admissible;

(ii) there exists $x_{0} \in X$ such that either $\alpha\left(x_{0}, f x_{0}\right) \geq 1$ or $\alpha\left(f x_{0}, x_{0}\right) \geq 1$;

(iii) $f$ is continuous.

Then $T$ has a fixed point.

Proof Following the lines in the proof of Theorem 2.1, we conclude the result.

Theorem 2.7 Let $(X, d)$ be a complete metric space. Suppose that $f: X \rightarrow X$ is an $\alpha$ admissible contractive inequality of integral type III which satisfies

(i) $f$ is weak triangular $\alpha$-admissible;

(ii) there exists $x_{0} \in X$ such that either $\alpha\left(x_{0}, f x_{0}\right) \geq 1$ or $\alpha\left(f x_{0}, x_{0}\right) \geq 1$;

(iii) if $\left\{x_{n}\right\}$ is a sequence in $X$ such that $\alpha\left(x_{n}, x_{n+1}\right) \geq 1$ for all $n$ and $x_{n} \rightarrow x \in X$ as $n \rightarrow+\infty$, then $\alpha\left(x_{n}, x\right) \geq 1$ for all $n$.

Then $f$ has a fixed point. 
Proof The reasoning in Theorem 2.2 establishes the result.

Example 2.4 Suppose that $X=[0,1]$ with the usual metric. We consider a mapping $f$ : $X \rightarrow X$ defined by $f(x)=\frac{x}{6}$. Define the mapping $\alpha: X \times X \rightarrow[0,+\infty)$ by $\alpha(x, y)=1$ for all $x, y \in X$. Hence, $f$ is weak triangular $\alpha$-admissible. Define $\varphi \in \Phi_{1}$ by $\varphi(t)=t$. Let us define $\psi \in \Phi_{3}$ and $\phi \in \Phi_{2}$ by $\psi(t)=\frac{t}{2}$ and $\phi(t)=\frac{t}{3}$ respectively for all $t \geq 0$.

Clearly, in view of the definitions of $\alpha$ and $f$, we infer that $f$ is an $\alpha$-admissible contractive inequality of integral type $I I I$. There exists $x_{0} \in X$ such that $\alpha\left(x_{0}, f x_{0}\right) \geq 1$. In fact, for $x_{0}=0$, we obtain

$$
\alpha(1, f 1)=\alpha\left(1, \frac{1}{6}\right)=1
$$

Clearly, $f$ is continuous. Now, all the hypotheses of Theorem 2.6 are satisfied. Thus $f$ has a fixed point in $X$. In this case, 0 is a fixed point of $f$.

Example 2.5 Suppose that $X=\left\{\frac{1}{n}: n \in \mathbb{N}\right\} \cup\{0\}$ with the usual metric $d(x, y)=|x-y|$ induced by $\mathbb{R}$. It is a complete metric space, since $X$ is a closed subset of $\mathbb{R}$. We consider a mapping $f: X \rightarrow X$ defined by

$$
f(x)= \begin{cases}\frac{1}{n+1} & \text { if } x=\frac{1}{n} \\ 0 & \text { if } x=0\end{cases}
$$

Define the mapping $\alpha: X \times X \rightarrow[0,+\infty)$ by $\alpha(x, y)=1$ for all $x, y \in X$. It is clear that $f$ is weak triangular $\alpha$-admissible. Thus, the condition (i) of Theorem 2.7 is satisfied.

Now, consider the following auxiliary function $\varphi$ defined as

$$
\varphi(t)= \begin{cases}0 & \text { if } t=0, \\ t^{(1 / t)-2}[1-\log t] & \text { if } 0<t<1, \\ 1 & \text { if } t \geq 1 .\end{cases}
$$

Then, for any $\varepsilon>0$, we have $\int_{0}^{\varepsilon} \varphi(t) d t=\varepsilon^{1 / \varepsilon}$ for $0<\varepsilon<1$ and $\int_{0}^{\varepsilon} \varphi(t) d t=\varepsilon$ for $\varepsilon \geq 1$. Consequently, we have $\varphi \in \Phi_{1}$.

Clearly, in view of the definitions of $\alpha$ and $f$, we infer that $f$ is an $\alpha$-admissible contractive inequality of integral type $I I I$ for $\psi(t)=\frac{t}{2}$ and $\phi(t)=\frac{t}{3}$, for all $t \geq 0$, where $\psi \in \Phi_{3}$ and $\phi \in \Phi_{2}$.

There exists $x_{0} \in X$ such that $\alpha\left(x_{0}, f x_{0}\right) \geq 1$. In fact, for example, for $x_{0}=0$, we obtain $\alpha(0, f 0)=\alpha(0,0)=1$. Hence, the condition (ii) of Theorem 2.7 is fulfilled.

Let $\left\{x_{n}\right\}$ be a sequence in $X$ such that $\alpha\left(x_{n}, x_{n+1}\right) \geq 1$ for all $n$ and $x_{n} \rightarrow x$ as $n \rightarrow+\infty$ for some $x \in X$. From the definition of $\alpha$, for all $n$, we have $\alpha\left(x_{n}, x\right)=1$ for all. So, the last condition of Theorem 2.7 is satisfied. As a result, due to Theorem 2.7, the mapping $f$ has a fixed point. Notice that $u=0$ is a fixed point of $f$.

Theorem 2.8 If the condition $\left(U^{*}\right)$ is added to the hypotheses of Theorem 2.6 (respectively, Theorem 2.7), then the fixed point $u$ of $T$ is unique. 


\section{Consequences in metric spaces}

We get the following result by letting $\alpha(x, y)=1$ in Theorem 2.5 .

Theorem 3.1 Let $f$ be a mapping from a complete metric space $(X, d)$ into itself satisfying, for all $x, y \in X$,

$$
\begin{aligned}
\psi\left(\int_{0}^{d(f x, f y)} \varphi(t) d t\right) \leq & \psi\left(\int_{0}^{M^{*}(x, y)} \varphi(t) d t\right)-\phi\left(\int_{0}^{N^{*}(x, y)} \varphi(t) d t\right) \\
& +L \psi\left(\int_{0}^{O(x, y)} \varphi(t) d t\right),
\end{aligned}
$$

where $M^{*}(x, y)=\max \left\{d(x, y), \frac{1}{2}[d(x, f x), d(y, f y)], \frac{1}{2}[d(x, f y)+d(y, f x)]\right\}, N^{*}(x, y)=\max \{d(x$, $\left.y), \frac{1}{2}[d(x, f x), d(y, f y)]\right\}, O(x, y)=\min \{d(x, f x), d(y, f y), d(y, f x), d(x, f y)\}$ and $(\varphi, \phi, \psi) \in \Phi_{1} \times$ $\Phi_{2} \times \Phi_{3}$. Then $f$ has a unique fixed point $a \in X$ such that $\lim _{n \rightarrow \infty} f^{n} x=$ a for each $x \in X$.

If we take $L=0$ in Theorem 3.1, we get the following result.

Theorem 3.2 Let $f$ be a mapping from a complete metric space $(X, d)$ into itself satisfying, for all $x, y \in X$,

$$
\psi\left(\int_{0}^{d(f x, f y)} \varphi(t) d t\right) \leq \psi\left(\int_{0}^{M^{*}(x, y)} \varphi(t) d t\right)-\phi\left(\int_{0}^{N^{*}(x, y)} \varphi(t) d t\right)
$$

where $M^{*}(x, y)=\max \left\{d(x, y), \frac{1}{2}[d(x, f x), d(y, f y)], \frac{1}{2}[d(x, f y)+d(y, f x)]\right\}, N(x, y)=\max \{d(x, y)$, $\left.\frac{1}{2}[d(x, f x), d(y, f y)]\right\}$ and $(\varphi, \phi, \psi) \in \Phi_{1} \times \Phi_{2} \times \Phi_{3}$. Then $f$ has a unique fixed point $a \in X$ such that $\lim _{n \rightarrow \infty} f^{n} x=$ a for each $x \in X$.

If we take $\psi(t)=t$ in Theorem 3.2, we get the following result.

Theorem 3.3 Letf be a mapping from a complete metric space $(X, d)$ into itself satisfying, for all $x, y \in X$,

$$
\int_{0}^{d(f x, f y)} \varphi(t) d t \leq \int_{0}^{M^{*}(x, y)} \varphi(t) d t-\phi\left(\int_{0}^{N^{*}(x, y)} \varphi(t) d t\right)
$$

where $M^{*}(x, y)=\max \left\{d(x, y), \frac{1}{2}[d(x, f x)+d(y, f y)], \frac{1}{2}[d(x, f y)+d(y, f x)]\right\}, N^{*}(x, y)=\max \{d(x$, $\left.y), \frac{1}{2}[d(x, f x)+d(y, f y)]\right\}$ and $(\varphi, \phi) \in \Phi_{1} \times \Phi_{2}$. Then $f$ has a unique fixed point $a \in X$ such that $\lim _{n \rightarrow \infty} f^{n} x=$ a for each $x \in X$.

Remark 3.1 The following theorem is the main result of [11] that can be easily deduced by taking $\alpha(x, y)=1$, for all $x, y \in X$, in Theorem 2.8. Consequently, all corollaries of the main result of [11] can be deduced evidently.

Theorem 3.4 Letf be a mapping from a complete metric space $(X, d)$ into itself satisfying, for all $x, y \in X$,

$$
\psi\left(\int_{0}^{d(f x, f y)} \varphi(t) d t\right) \leq \psi\left(\int_{0}^{d(x, y)} \varphi(t) d t\right)-\phi\left(\int_{0}^{d(x, y)} \varphi(t) d t\right)
$$


where $(\varphi, \phi, \psi) \in \Phi_{1} \times \Phi_{2} \times \Phi_{3}$. Then $f$ has a unique fixed point $a \in X$ such that $\lim _{n \rightarrow \infty} f^{n} x=$ a for each $x \in X$.

If we take $\psi(t)=t$ in Theorem 3.4, we get the following result.

Theorem 3.5 Let $f$ be a mapping from a complete metric space $(X, d)$ into itself satisfying, for all $x, y \in X$,

$$
\int_{0}^{d(f x, f y)} \varphi(t) d t \leq \int_{0}^{d(x, y)} \varphi(t) d t-\phi\left(\int_{0}^{d(x, y)} \varphi(t) d t\right)
$$

where $(\varphi, \phi) \in \Phi_{1} \times \Phi_{2}$. Then $f$ has a unique fixed point $a \in X$ such that $\lim _{n \rightarrow \infty} f^{n} x=a$ for each $x \in X$.

Theorem 3.6 Let $f$ be a mapping from a complete metric space $(X, d)$ into itself. If there is $k \in[0,1)$ satisfying the following condition for all $x, y \in X$ :

$$
\int_{0}^{d(f x, f y)} \varphi(t) d t \leq k \int_{0}^{d(x, y)} \varphi(t) d t
$$

then $f$ has a unique fixed point $a \in X$ such that $\lim _{n \rightarrow \infty} f^{n} x=$ a for each $x \in X$.

\section{Consequences in partially ordered metric spaces}

Definition 4.1 Let $(X, \preceq)$ be a partially ordered set and $T: X \rightarrow X$ be a given mapping. We say that $T$ is nondecreasing with respect to $\preceq$ if

$$
x, y \in X, \quad x \preceq y \quad \Longrightarrow \quad T x \preceq T y \text {. }
$$

Definition 4.2 Let $(X, \preceq)$ be a partially ordered set. A sequence $\left\{x_{n}\right\} \subset X$ is said to be nondecreasing with respect to $\preceq$ if $x_{n} \preceq x_{n+1}$ for all $n$.

Definition 4.3 Let $(X, \preceq)$ be a partially ordered set and $d$ be a metric on $X$. We say that $(X, \preceq, d)$ is regular if for every nondecreasing sequence $\left\{x_{n}\right\} \subset X$ such that $x_{n} \rightarrow x \in X$ as $n \rightarrow \infty$, there exists a subsequence $\left\{x_{n(k)}\right\}$ of $\left\{x_{n}\right\}$ such that $x_{n(k)} \preceq x$ for all $k$.

We have the following result.

Corollary 4.1 Let $(X, \preceq)$ be a partially ordered set and $d$ be a metric on $X$ such that $(X, d)$ is complete. Let $f: X \rightarrow X$ be a nondecreasing mapping with respect to $\preceq$ and satisfy the following inequality:

$$
\begin{aligned}
\psi\left(\int_{0}^{d(f x, f y)} \varphi(t) d t\right) \leq & \psi\left(\int_{0}^{M^{*}(x, y)} \varphi(t) d t\right)-\phi\left(\int_{0}^{N^{*}(x, y)} \varphi(t) d t\right) \\
& +L \psi\left(\int_{0}^{O(x, y)} \varphi(t) d t\right)
\end{aligned}
$$

for all $x, y \in X$ with $x \succeq y$, where $M^{*}(x, y)=\max \left\{d(x, y), \frac{1}{2}[d(x, f x)+d(y, f y)], \frac{1}{2}[d(x, f y)+\right.$ $d(y, f x)]\}, N^{*}(x, y)=\max \left\{d(x, y), \frac{1}{2}[d(x, f x)+d(y, f y)]\right\}, O(x, y)=\min \{d(x, f x), d(y, f y), d(y, f x)$, $d(x, f y)\}$ and $(\varphi, \phi, \psi) \in \Phi_{1} \times \Phi_{2} \times \Phi_{3}$. Suppose also that the following conditions hold: 
(i) there exists $x_{0} \in X$ such that $x_{0} \preceq f x_{0}$;

(ii) $f$ is continuous or $(X, \preceq, d)$ is regular.

Then $f$ has a fixed point. Moreover, if for all $x, y \in X$ there exists $z \in X$ such that $x \leq z$ and $y \preceq z$, we have uniqueness of the fixed point.

Proof Define the mapping $\alpha: X \times X \rightarrow[0, \infty)$ by

$$
\alpha(x, y)= \begin{cases}1 & \text { if } x \leq y \text { or } x \geq y \\ 0 & \text { otherwise }\end{cases}
$$

Clearly, $f$ is an $\alpha$-admissible contractive inequality of integral type $I$. From condition (i), we have $\alpha\left(x_{0}, f x_{0}\right) \geq 1$. Moreover, for all $x, y \in X$, from the monotone property of $f$, we have

$$
\alpha(x, y) \geq 1 \quad \Longrightarrow \quad x \geq y \text { or } x \preceq y \quad \Longrightarrow \quad f x \succeq f y \text { or } f x \preceq f y \quad \Longrightarrow \quad \alpha(f x, f y) \geq 1 .
$$

Thus $f$ is $\alpha$-admissible. Now, if $f$ is continuous, the existence of a fixed point follows from Theorem 2.1. Suppose now that $(X, \preceq, d)$ is regular. Let $\left\{x_{n}\right\}$ be a sequence in $X$ such that $\alpha\left(x_{n}, x_{n+1}\right) \geq 1$ for all $n$ and $x_{n} \rightarrow x \in X$ as $n \rightarrow \infty$. From the regularity hypothesis, there exists a subsequence $\left\{x_{n(k)}\right\}$ of $\left\{x_{n}\right\}$ such that $x_{n(k)} \preceq x$ for all $k$. This implies from the definition of $\alpha$ that $\alpha\left(x_{n(k)}, x\right) \geq 1$ for all $k$. In this case, the existence of a fixed point follows from Theorem 2.2. To show the uniqueness, let $x, y \in X$. By hypothesis, there exists $z \in X$ such that $x \preceq z$ and $y \preceq z$, which implies from the definition of $\alpha$ that $\alpha(x, z) \geq 1$ and $\alpha(y, z) \geq 1$. Thus we deduce the uniqueness of the fixed point by Theorem 2.5 .

The following result is an immediate consequence of Corollary 4.1.

Corollary 4.2 Let $(X, \preceq)$ be a partially ordered set and $d$ be a metric on $X$ such that $(X, d)$ is complete. Let $T: X \rightarrow X$ be a nondecreasing mapping with respect to $\preceq$. Suppose that there exists a function $\psi \in \Psi$ such that

$$
d(T x, T y) \leq \psi(d(x, y))
$$

for all $x, y \in X$ with $x \geq y$. Suppose also that the following conditions hold:

(i) there exists $x_{0} \in X$ such that $x_{0} \preceq T x_{0}$;

(ii) $T$ is continuous or $(X, \preceq, d)$ is regular.

Then $T$ has a fixed point. Moreover, iffor all $x, y \in X$ there exists $z \in X$ such that $x \preceq z$ and $y \preceq z$, we have uniqueness of the fixed point.

Remark 4.1 Let $\left\{A_{i}\right\}_{i=1}^{2}$ be nonempty closed subsets of a complete metric space $(X, d)$ and $T: Y \rightarrow Y$ be a given mapping, where $Y=A_{1} \cup A_{2}$. If the following condition holds:

$$
T\left(A_{1}\right) \subseteq A_{2} \quad \text { and } \quad T\left(A_{2}\right) \subseteq A_{1}
$$

then $T$ is called a cyclic mapping. Since $A_{1}$ and $A_{2}$ are closed subsets of the complete metric space $(X, d)$, then $(Y, d)$ is complete. Define the mapping $\alpha: Y \times Y \rightarrow[0, \infty)$ by

$$
\alpha(x, y)= \begin{cases}1 & \text { if }(x, y) \in\left(A_{1} \times A_{2}\right) \cup\left(A_{2} \times A_{1}\right), \\ 0 & \text { otherwise. }\end{cases}
$$


By using the observation above, it is possible to deduce some fixed point results of a cyclic mapping that satisfies, e.g., one of the inequalities between (31)-(36), and so on. For more details on such approach, we refer, e.g., to $[14,16]$.

\section{Further results}

Theorem 5.1 Let $(X, d)$ be a complete metric space, $f: X \rightarrow X$ and $\alpha: X \times X \rightarrow[0,+\infty)$ be self-mappings. Suppose that there exist $(\varphi, \psi, \gamma) \in \Phi_{1} \times \Phi_{3} \times \Phi_{5}$ and $L \geq 0$ such that

$$
\begin{aligned}
\alpha(x, y) \psi\left(\int_{0}^{d(f x, f y)} \varphi(t) d t\right) \leq & \gamma(M(x, y)) \psi\left(\int_{0}^{M(x, y)} \varphi(t) d t\right) \\
& +L \psi\left(\int_{0}^{O(x, y)} \varphi(t) d t\right),
\end{aligned}
$$

for all $x, y \in X$, where

$$
M(x, y)=\max \left\{d(x, y), d(x, f x), d(y, f y), \frac{1}{2}[d(x, f y)+d(y, f x)]\right\},
$$

and

$$
O(x, y)=\min \{d(x, f x), d(y, f y), d(y, f x), d(x, f y)\}
$$

Suppose also that the following conditions hold:

(i) $f$ is weak triangular $\alpha$-admissible;

(ii) there exists $x \in X$ such that $x \preceq f x$;

(iii) $f$ is continuous or $(X, \preceq, d)$ is regular.

Then $f$ has a unique fixed point $a \in X$ such that $\lim _{n \rightarrow \infty} f^{n} x=a$ for each $x \in X$.

Proof From (ii), there exits a point $x \in X$ such that $\alpha(x, f x) \geq 1$ (due to the symmetry of the metric, the other case yields the same result). Let $x_{0}=x$ and consider an iterative sequence $\left\{x_{n}\right\}$ in $X$ by $x_{n+1}=f x_{n}$ for all $n \geq 0$. Note that we have

$$
\alpha\left(x_{0}, x_{1}\right)=\alpha\left(x_{0}, f x_{0}\right) \geq 1 \quad \Rightarrow \quad \alpha\left(f x_{0}, f x_{1}\right)=\alpha\left(x_{1}, x_{2}\right) \geq 1
$$

By mathematical induction, we get

$$
\alpha\left(x_{n}, x_{n+1}\right) \geq 1 \quad \text { for all } n \in \mathbb{N}_{0} .
$$

Let us denote

$$
d_{n}=d\left(x_{n}, x_{n+1}\right) \quad \text { and } \quad \alpha_{n}=\alpha\left(x_{n}, x_{n+1}\right) \quad \text { for } n \in \mathbb{N}_{0} \text {. }
$$

Now, if $x_{n_{0}}=x_{n_{0}+1}$ for some $n_{0}$, then $u=x_{n_{0}}$ is a fixed point of $f$. This completes the proof. Consequently, suppose $x_{n} \neq x_{n+1}$ for all $n \in \mathbb{N}_{0}$, that is,

$$
0<d_{n}=d\left(x_{n}, x_{n+1}\right) \quad \text { for all } n \in \mathbb{N}_{0} \text {. }
$$


Now, we proceed to show that $\left\{d_{n}\right\}$ is a non-increasing sequence of real numbers, that is,

$$
d_{n} \leq d_{n-1}, \quad \forall n \in \mathbb{N} .
$$

Suppose, on the contrary, that inequality (42) does not hold. Thus, there exists some $n_{0} \in$ $\mathbb{N}$ such that

$$
d_{n_{0}}>d_{n_{0}-1}
$$

From (41) and (43), we get

$$
0<\int_{0}^{d_{n_{0}-1}} \varphi(t) d t<\int_{0}^{d_{n_{0}}} \varphi(t) d t
$$

Regarding again (41) and (43) together with the properties of $\psi$, we conclude that

$$
0=\psi(0)<\psi\left(\int_{0}^{d_{n_{0}-1}} \varphi(t) d t\right) \leq \psi\left(\int_{0}^{d_{n_{0}}} \varphi(t) d t\right) .
$$

Using equations (38)-(40), (45) we obtain that

$$
\begin{aligned}
\psi\left(\int_{0}^{d_{n_{0}-1}} \varphi(t) d t\right) \leq & \alpha_{n_{0}} \psi\left(\int_{0}^{d_{n_{0}-1}} \varphi(t) d t\right) \\
\leq & \alpha_{n_{0}} \psi\left(\int_{0}^{d_{n_{0}}} \varphi(t) d t\right)=\alpha_{n_{0}} \psi\left(\int_{0}^{d\left(f^{n_{0}} x f^{n_{0}+1} x\right)} \varphi(t) d t\right) \\
\leq & \gamma\left(M\left(f^{n_{0}-1} x, f^{n_{0}} x\right)\right) \psi\left(\int_{0}^{M\left(f^{n_{0}-1} x f^{\left.n_{0} x\right)}\right.} \varphi(t) d t\right) \\
& +L \psi\left(\int_{0}^{O\left(f^{n_{0}-1} x f^{\left.n_{0} x\right)}\right.} \varphi(t) d t\right),
\end{aligned}
$$

where

$$
\begin{aligned}
M\left(f^{n_{0}-1} x, f^{n_{0}} x\right) \leq & \max \left\{d\left(f^{n_{0}-1} x, f^{n_{0}} x\right), d\left(f^{n_{0}} x, f^{n_{0}+1} x\right)\right\}=\max \left\{d_{n_{0}-1}, d_{n_{0}}\right\}, \\
O\left(f^{n_{0}-1} x, f^{n_{0}} x\right)= & \min \left\{d\left(f^{n_{0}-1} x, f^{n_{0}} x\right), d\left(f^{n_{0}} x, f^{n_{0}+1} x\right), d\left(f^{n_{0}} x, f^{n_{0}} x\right),\right. \\
& \left.d\left(f^{n_{0}-1} x, f^{n_{0}+1} x\right)\right\}=0 .
\end{aligned}
$$

From (43), we have $M\left(f^{n_{0}-1} x, f^{n_{0}} x\right) \leq d_{n_{0}}$. Hence, inequality (46) implies

$$
\begin{aligned}
\psi\left(\int_{0}^{d_{n_{0}-1}} \varphi(t) d t\right) & \leq \alpha_{n_{0}} \psi\left(\int_{0}^{d_{n_{0}-1}} \varphi(t) d t\right) \leq \alpha_{n_{0}} \psi\left(\int_{0}^{d_{n_{0}}} \varphi(t) d t\right) \\
& \leq \gamma\left(d_{n_{0}}\right) \psi\left(\int_{0}^{d_{n_{0}}} \varphi(t) d t\right) \\
& <\psi\left(\int_{0}^{d_{n_{0}}} \varphi(t) d t\right),
\end{aligned}
$$

which contradicts inequality (44). Hence, (42) holds. Thus, there exists a constant $c \geq 0$ such that $\lim _{n \rightarrow \infty} d_{n}=c \geq 0$. 
Next we show that $c=0$, that is,

$$
\lim _{n \rightarrow \infty} d_{n}=0
$$

Suppose, on the contrary, that $c>0$. It follows from (38) and (39) that

$$
\begin{aligned}
\psi\left(\int_{0}^{d_{n}} \varphi(t) d t\right)= & \psi\left(\int_{0}^{d\left(f^{n} x, f^{n+1} x\right)} \varphi(t) d t\right) \\
\leq & \alpha_{n} \psi\left(\int_{0}^{d\left(f^{n} x, f^{n+1} x\right)} \varphi(t) d t\right) \\
\leq & \gamma\left(M\left(f^{n} x, f^{n-1} x\right)\right) \psi\left(\int_{0}^{M\left(f^{n} x, f^{n-1} x\right)} \varphi(t) d t\right) \\
& +L \psi\left(\int_{0}^{O\left(f^{n-1} x, f^{n} x\right)} \varphi(t) d t\right),
\end{aligned}
$$

where

$$
\begin{aligned}
& M\left(f^{n-1}, f^{n} x\right) \leq \max \left\{d\left(f^{n-1} x, f^{n} x\right), d\left(f^{n} x, f^{n+1} x\right)\right\}=\max \left\{d_{n-1}, d_{n}\right\}, \\
& O\left(f^{n-1} x, f^{n} x\right)=\min \left\{d\left(f^{n-1} x, f^{n} x\right), d\left(f^{n} x, f^{n+1} x\right), d\left(f^{n} x, f^{n} x\right), d\left(f^{n-1} x, f^{n+1} x\right)\right\}=0 .
\end{aligned}
$$

Hence, inequality (49) becomes

$$
\begin{aligned}
\psi\left(\int_{0}^{d_{n}} \varphi(t) d t\right) & =\psi\left(\int_{0}^{d\left(f^{n} x, f^{n+1} x\right)} \varphi(t) d t\right) \leq \alpha_{n} \psi\left(\int_{0}^{d\left(f^{n} x, f^{n+1} x\right)} \varphi(t) d t\right) \\
& \leq \gamma\left(d_{n-1}\right) \psi\left(\int_{0}^{d_{n-1}} \varphi(t) d t\right) .
\end{aligned}
$$

Taking the upper limit in (50) and using Lemma 1.1, we get

$$
\begin{aligned}
\psi\left(\int_{0}^{c} \varphi(t) d t\right) & =\lim _{n \rightarrow \infty} \sup \psi\left(\int_{0}^{d_{n}} \varphi(t) d t\right) \\
& \leq \lim _{n \rightarrow \infty} \sup \left[\gamma\left(d_{n-1}\right) \psi\left(\int_{0}^{d_{n-1}} \varphi(t) d t\right)\right] \\
& \leq \lim _{n \rightarrow \infty} \sup \left[\gamma\left(d_{n-1}\right)\right] \cdot \lim _{n \rightarrow \infty} \sup \left[\psi\left(\int_{0}^{d_{n-1}} \varphi(t) d t\right)\right] \\
& <\psi\left(\int_{0}^{c} \varphi(t) d t\right)
\end{aligned}
$$

which is a contradiction. Hence $c=0$.

Next we show that $\left\{f^{n} x\right\}_{n \in \mathbb{N}}$ is a Cauchy sequence. Suppose, on the contrary, that $\left\{f^{n} x\right\}_{n \in \mathbb{N}}$ is not a Cauchy sequence. Thus, there is a constant $\epsilon>0$ such that for each positive integer $k$, there are positive integers $m(k)$ and $n(k)$ with $m(k)>n(k)>k$ satisfying

$$
d\left(f^{m(k)} x, f^{n(k)} x\right)>\epsilon .
$$


For each positive integer $k$, let $m(k)$ denote the least integer exceeding $n(k)$ and satisfying (52). This implies that

$$
d\left(f^{m(k)} x, f^{n(k)} x\right)>\epsilon \quad \text { and } \quad d\left(f^{m(k)-1} x, f^{n(k)} x\right) \leq \epsilon \quad \text { for all } k \in \mathbb{N} .
$$

On the other hand, we have

$$
\begin{aligned}
& d\left(f^{m(k)} x, f^{n(k)} x\right) \leq d\left(f^{n(k)} x, f^{m(k)-1} x\right)+d_{m(k)-1}, \quad \forall k \in \mathbb{N}, \\
& \left|d\left(f^{m(k)} x, f^{n(k)+1} x\right)-d\left(f^{m(k)} x, f^{n(k)} x\right)\right| \leq d_{n(k)}, \quad \forall k \in \mathbb{N}, \\
& \left|d\left(f^{m(k)+1} x, f^{n(k)+1} x\right)-d\left(f^{m(k)} x, f^{n(k)+1} x\right)\right| \leq d_{m(k)}, \quad \forall k \in \mathbb{N}, \\
& \left|d\left(f^{m(k)+1} x, f^{n(k)+1} x\right)-d\left(f^{m(k)+1} x, f^{n(k)+2} x\right)\right| \leq d_{n(k)+1}, \quad \forall k \in \mathbb{N} .
\end{aligned}
$$

In view of (53) and (54), we infer that

$$
\begin{aligned}
& \lim _{k \rightarrow \infty} d\left(f^{n(k)} x, f^{m(k)} x\right)=\epsilon, \\
& \lim _{k \rightarrow \infty} d\left(f^{m(k)} x, f^{n(k)+1} x\right)=\epsilon, \\
& \lim _{k \rightarrow \infty} d\left(f^{m(k)+1} x, f^{n(k)+1} x\right)=\epsilon, \\
& \lim _{k \rightarrow \infty} d\left(f^{m(k)+1} x, f^{n(k)+2} x\right)=\epsilon .
\end{aligned}
$$

Using the weak triangular alpha admissible property of $f$, we get in view of (39)

$$
\alpha\left(f^{m(k)} x, f^{n(k)+1} x\right) \geq 1 .
$$

From (38) and (56), we have, for all $k \in \mathbb{N}$,

$$
\begin{aligned}
& \psi\left(\int_{0}^{d\left(f^{m(k)+1} x, f^{n(k)+2} x\right)} \varphi(t) d t\right) \\
& \leq \alpha\left(f^{m(k)} x, f^{n(k)+1} x\right) \psi\left(\int_{0}^{\left.d f^{m(k)+1} x_{f} f^{n(k)+2} x\right)} \varphi(t) d t\right) \\
& \quad \leq \gamma\left(M\left(f^{m(k)} x, f^{n(k)+1}\right)\right) \psi\left(\int_{0}^{M\left(f^{m(k)} x, f^{n(k)+1}\right)} \varphi(t) d t\right) \\
& \quad+L \psi\left(\int_{0}^{O\left(f^{m(k)} x, f^{n(k)+1}\right)} \varphi(t) d t\right) .
\end{aligned}
$$

Taking the upper limit in (57) and using (55) and Lemma 1.1, we get

$$
\begin{aligned}
\psi\left(\int_{0}^{\epsilon} \varphi(t) d t\right) & =\lim _{k \rightarrow \infty} \sup \psi\left(\int_{0}^{d\left(f^{m(k)+1} x f^{n(k)+2} x\right)} \varphi(t) d t\right) \\
& \leq \lim _{k \rightarrow \infty} \sup \alpha\left(f^{m(k)} x, f^{n(k)+1} x\right) \psi\left(\int_{0}^{d\left(f^{m(k)+1} x f^{n(k)+2} x\right)} \varphi(t) d t\right) \\
& \leq \lim _{k \rightarrow \infty} \sup \gamma\left(M\left(f^{m(k)} x, f^{n(k)+1} x\right)\right) \psi\left(\int_{0}^{M\left(f^{m(k)} x f^{n(k)+1} x\right)} \varphi(t) d t\right)
\end{aligned}
$$




$$
\begin{aligned}
& \quad+L \lim _{k \rightarrow \infty} \sup \psi\left(\int_{0}^{O\left(f^{m(k)} x f^{n(k)+1}\right)} \varphi(t) d t\right) \\
& <\psi\left(\int_{0}^{\epsilon} \varphi(t) d t\right),
\end{aligned}
$$

which is impossible. Thus $\left\{f^{n} x\right\}_{n \in \mathbb{N}}$ is a Cauchy sequence. Now, since $(X, d)$ is complete, there exists a point $a \in X$ such that $\lim _{n \rightarrow \infty} f^{n} x=a$. From the continuity of $f$, it follows that $x_{n}=f x_{n+1} \rightarrow f u$ as $n \rightarrow+\infty$. From the uniqueness of limits, we get $a=f a$, that is, $u$ is a fixed point of $f$. This completes the proof.

Theorem 5.2 Let $(X, d)$ be a complete metric space and $f: X \rightarrow X$ be a self-mapping. Suppose that there exist $(\varphi, \phi, \psi) \in \Phi_{1} \times \Phi_{2} \times \Phi_{3}$ with $\phi(t) \leq \psi(t)$ for all $t \in \mathbb{R}^{+}, \beta \in \Phi_{5}$, $\alpha: X \times X \rightarrow[0,+\infty)$ and $L \geq 0$ such that

$$
\begin{aligned}
\alpha(x, y) \psi\left(\int_{0}^{d(f x, f y)} \varphi(t) d t\right) \leq & \beta(M(x, y)) \phi\left(\int_{0}^{M(x, y)} \varphi(t) d t\right) \\
& +L \psi\left(\int_{0}^{O(x, y)} \varphi(t) d t\right)
\end{aligned}
$$

for all $x, y \in X$, where

$$
M(x, y)=\max \left\{d(x, y), d(x, f x), d(y, f y), \frac{1}{2}[d(x, f y)+d(y, f x)]\right\},
$$

and

$$
O(x, y)=\min \{d(x, f x), d(y, f y), d(y, f x), d(x, f y)\}
$$

Suppose also that the following conditions hold:

(i) $f$ is weak triangular $\alpha$-admissible;

(ii) there exists $x \in X$ such that $x \preceq f x$;

(iii) $f$ is continuous or $(X, \preceq, d)$ is regular.

Then $f$ has a unique fixed point $a \in X$ such that $\lim _{n \rightarrow \infty} f^{n} x=a$ for each $x \in X$.

Proof From condition (ii), there exists a point $x \in X$ such that $\alpha(x, f x) \geq 1$ (due to the symmetry of the metric, the other case yields the same result). Let $x_{0}=x$ and let the iterative sequence $\left\{x_{n}\right\}$ in $X$ be defined by $x_{n+1}=f x_{n}$ for all $n \geq 0$. Note that we have

$$
\alpha\left(x_{0}, x_{1}\right)=\alpha\left(x_{0}, f x_{0}\right) \geq 1 \quad \Rightarrow \quad \alpha\left(f x_{0}, f x_{1}\right)=\alpha\left(x_{1}, x_{2}\right) \geq 1 .
$$

Using mathematical induction, we obtain

$$
\alpha\left(x_{n}, x_{n+1}\right) \geq 1 \quad \text { for all } n \in \mathbb{N}_{0} .
$$

Set

$$
d_{n}=d\left(x_{n}, x_{n+1}\right) \quad \text { and } \quad \alpha_{n}=\alpha\left(x_{n}, x_{n+1}\right) \quad \text { for } n \in \mathbb{N}_{0} .
$$


If for some $n_{0}, x_{n_{0}}=x_{n_{0}+1}$, then $u=x_{n_{0}}$ is a fixed point of $f$. This completes the proof. Suppose that $x_{n} \neq x_{n+1}$ for all $n \in \mathbb{N}_{0}$, that is,

$$
0<d_{n}=d\left(x_{n}, x_{n+1}\right) \quad \text { for all } n \in \mathbb{N}_{0} .
$$

Now, we need to show that $\left\{d_{n}\right\}$ is a non-increasing sequence of real numbers, that is,

$$
d_{n} \leq d_{n-1}, \quad \forall n \in \mathbb{N} .
$$

Suppose, on the contrary, that inequality (62) does not hold. Thus, there exists some $n_{0} \in$ $\mathbb{N}$ such that

$$
d_{n_{0}}>d_{n_{0}-1}
$$

From (61) and (63), we get

$$
0<\int_{0}^{d_{n_{0}-1}} \varphi(t) d t<\int_{0}^{d_{n_{0}}} \varphi(t) d t
$$

From equations (61) and (63) and using the properties of $\psi$, we get

$$
0=\psi(0)<\psi\left(\int_{0}^{d_{n_{0}-1}} \varphi(t) d t\right) \leq \psi\left(\int_{0}^{d_{n_{0}}} \varphi(t) d t\right) .
$$

In view of equations (58)-(60), (65) we infer that

$$
\begin{aligned}
\psi\left(\int_{0}^{d_{n_{0}-1}} \varphi(t) d t\right) \leq & \alpha_{n_{0}} \psi\left(\int_{0}^{d_{n_{0}-1}} \varphi(t) d t\right) \\
\leq & \alpha_{n_{0}} \psi\left(\int_{0}^{d_{n_{0}}} \varphi(t) d t\right)=\alpha_{n_{0}} \psi\left(\int_{0}^{d l\left(f^{n_{0}} x_{f} f^{n_{0}+1} x\right)} \varphi(t) d t\right) \\
\leq & \beta\left(M\left(f^{n_{0}-1} x, f^{n_{0}} x\right)\right) \phi\left(\int_{0}^{M\left(f^{n_{0}-1} x_{f} f^{\left.n_{0} x\right)}\right.} \varphi(t) d t\right) \\
& +L \psi\left(\int_{0}^{O\left(f^{n_{0}-1} x f^{n_{0}} x\right)} \varphi(t) d t\right),
\end{aligned}
$$

where

$$
\begin{aligned}
M\left(f^{n_{0}-1} x, f^{n_{0}} x\right) \leq & \max \left\{d\left(f^{n_{0}-1} x, f^{n_{0}} x\right), d\left(f^{n_{0}} x, f^{n_{0}+1} x\right)\right\}=\max \left\{d_{n_{0}-1}, d_{n_{0}}\right\}, \\
O\left(f^{n_{0}-1} x, f^{n_{0}} x\right)= & \min \left\{d\left(f^{n_{0}-1} x, f^{n_{0}} x\right), d\left(f^{n_{0}} x, f^{n_{0}+1} x\right), d\left(f^{n_{0}} x, f^{n_{0}} x\right),\right. \\
& \left.d\left(f^{n_{0}-1} x, f^{n_{0}+1} x\right)\right\}=0 .
\end{aligned}
$$

From (63), we have $M\left(f^{n_{0}-1} x, f^{n_{0}} x\right) \leq d_{n_{0}}$. Hence, inequality (66) implies

$$
\begin{aligned}
\psi\left(\int_{0}^{d_{n_{0}-1}} \varphi(t) d t\right) & \leq \alpha_{n_{0}} \psi\left(\int_{0}^{d_{n_{0}-1}} \varphi(t) d t\right) \leq \alpha_{n_{0}} \psi\left(\int_{0}^{d_{n_{0}}} \varphi(t) d t\right) \\
& \leq \beta\left(d_{n_{0}}\right) \phi\left(\int_{0}^{d_{n_{0}}} \varphi(t) d t\right)
\end{aligned}
$$




$$
\begin{aligned}
& \leq \beta\left(d_{n_{0}}\right) \psi\left(\int_{0}^{d_{n_{0}}} \varphi(t) d t\right) \\
& <\psi\left(\int_{0}^{d_{n_{0}}} \varphi(t) d t\right)
\end{aligned}
$$

which contradicts inequality (64). Hence, (62) holds. Thus, there exists a constant $c \geq 0$ such that $\lim _{n \rightarrow \infty} d_{n}=c \geq 0$.

Next we show that $c=0$, that is,

$$
\lim _{n \rightarrow \infty} d_{n}=0
$$

Suppose, on the contrary, that $c>0$. It follows from (58) and (59) that

$$
\begin{aligned}
\psi\left(\int_{0}^{d_{n}} \varphi(t) d t\right)= & \psi\left(\int_{0}^{d\left(f^{n} x, f^{n+1} x\right)} \varphi(t) d t\right) \leq \alpha_{n} \psi\left(\int_{0}^{d\left(f^{n} x, f^{n+1} x\right)} \varphi(t) d t\right) \\
\leq & \beta\left(M\left(f^{n} x, f^{n-1} x\right)\right) \phi\left(\int_{0}^{M\left(f^{n} x, f^{n-1} x\right)} \varphi(t) d t\right) \\
& +L \psi\left(\int_{0}^{O\left(f^{n-1} x, f^{n} x\right)} \varphi(t) d t\right),
\end{aligned}
$$

where

$$
\begin{aligned}
& M\left(f^{n-1}, f^{n} x\right) \leq \max \left\{d\left(f^{n-1} x, f^{n} x\right), d\left(f^{n} x, f^{n+1} x\right)\right\}=\max \left\{d_{n-1}, d_{n}\right\}, \\
& O\left(f^{n-1} x, f^{n} x\right)=\min \left\{d\left(f^{n-1} x, f^{n} x\right), d\left(f^{n} x, f^{n+1} x\right), d\left(f^{n} x, f^{n} x\right), d\left(f^{n-1} x, f^{n+1} x\right)\right\}=0 .
\end{aligned}
$$

Hence, inequality (69) becomes

$$
\begin{aligned}
\psi\left(\int_{0}^{d_{n}} \varphi(t) d t\right) & =\psi\left(\int_{0}^{d\left(f^{n} x, f^{n+1} x\right)} \varphi(t) d t\right) \leq \alpha_{n} \psi\left(\int_{0}^{d\left(f^{n} x, f^{n+1} x\right)} \varphi(t) d t\right) \\
& \leq \beta\left(d_{n-1}\right) \phi\left(\int_{0}^{d_{n-1}} \varphi(t) d t\right) .
\end{aligned}
$$

Taking the upper limit in (70) and using Lemma 1.1, we get

$$
\begin{aligned}
\psi\left(\int_{0}^{c} \varphi(t) d t\right) & =\lim _{n \rightarrow \infty} \sup \psi\left(\int_{0}^{d_{n}} \varphi(t) d t\right) \\
& \leq \lim _{n \rightarrow \infty} \sup \left[\beta\left(d_{n-1}\right) \phi\left(\int_{0}^{d_{n-1}} \varphi(t) d t\right)\right] \\
& \leq \lim _{n \rightarrow \infty} \sup \left[\beta\left(d_{n-1}\right)\right] \cdot \lim _{n \rightarrow \infty} \sup \left[\phi\left(\int_{0}^{d_{n-1}} \varphi(t) d t\right)\right] \\
& \leq \lim _{n \rightarrow \infty} \sup \left[\beta\left(d_{n-1}\right)\right] \cdot \lim _{n \rightarrow \infty} \sup \left[\psi\left(\int_{0}^{d_{n-1}} \varphi(t) d t\right)\right] \\
& <\psi\left(\int_{0}^{c} \varphi(t) d t\right),
\end{aligned}
$$

which is a contradiction. Hence $c=0$. 
Now, we show that $\left\{f^{n} x\right\}_{n \in \mathbb{N}}$ is a Cauchy sequence. Suppose, on the contrary, that $\left\{f^{n} x\right\}_{n \in \mathbb{N}}$ is not a Cauchy sequence. Thus, there is a constant $\epsilon>0$ such that for each positive integer $k$, there are positive integers $m(k)$ and $n(k)$ with $m(k)>n(k)>k$ satisfying

$$
d\left(f^{m(k)} x, f^{n(k)} x\right)>\epsilon .
$$

For each positive integer $k$, let $m(k)$ denote the least integer exceeding $n(k)$ and satisfying (72). This implies that

$$
d\left(f^{m(k)} x, f^{n(k)} x\right)>\epsilon \quad \text { and } \quad d\left(f^{m(k)-1} x, f^{n(k)} x\right) \leq \epsilon \quad \text { for all } k \in \mathbb{N} .
$$

On the other hand, we have

$$
\begin{aligned}
& d\left(f^{m(k)} x, f^{n(k)} x\right) \leq d\left(f^{n(k)} x, f^{m(k)-1} x\right)+d_{m(k)-1}, \quad \forall k \in \mathbb{N}, \\
& \left|d\left(f^{m(k)} x, f^{n(k)+1} x\right)-d\left(f^{m(k)} x, f^{n(k)} x\right)\right| \leq d_{n(k)}, \quad \forall k \in \mathbb{N}, \\
& \left|d\left(f^{m(k)+1} x, f^{n(k)+1} x\right)-d\left(f^{m(k)} x, f^{n(k)+1} x\right)\right| \leq d_{m(k)}, \quad \forall k \in \mathbb{N}, \\
& \left|d\left(f^{m(k)+1} x, f^{n(k)+1} x\right)-d\left(f^{m(k)+1} x, f^{n(k)+2} x\right)\right| \leq d_{n(k)+1}, \quad \forall k \in \mathbb{N} .
\end{aligned}
$$

In view of (73) and (74), we infer that

$$
\begin{aligned}
& \lim _{k \rightarrow \infty} d\left(f^{n(k)} x, f^{m(k)} x\right)=\epsilon, \\
& \lim _{k \rightarrow \infty} d\left(f^{m(k)} x, f^{n(k)+1} x\right)=\epsilon, \\
& \lim _{k \rightarrow \infty} d\left(f^{m(k)+1} x, f^{n(k)+1} x\right)=\epsilon, \\
& \lim _{k \rightarrow \infty} d\left(f^{m(k)+1} x, f^{n(k)+2} x\right)=\epsilon .
\end{aligned}
$$

Using the weak triangular alpha admissible property of $f$, we get in view of (59)

$$
\alpha\left(f^{m(k)} x, f^{n(k)+1} x\right) \geq 1
$$

From (58) and (76), we have, for all $k \in \mathbb{N}$,

$$
\begin{aligned}
\psi\left(\int_{0}^{d\left(f^{m(k)+1} x, f^{n(k)+2} x\right)} \varphi(t) d t\right) \leq & \alpha\left(f^{m(k)} x, f^{n(k)+1} x\right) \psi\left(\int_{0}^{d\left(f^{m(k)+1} x, f^{n(k)+2} x\right)} \varphi(t) d t\right) \\
\leq & \beta\left(M\left(f^{m(k)} x, f^{n(k)+1}\right)\right) \phi\left(\int_{0}^{M\left(f^{m(k)} x, f^{n(k)+1}\right)} \varphi(t) d t\right) \\
& +L \psi\left(\int_{0}^{O\left(f^{m(k)} x f^{n(k)+1}\right)} \varphi(t) d t\right) .
\end{aligned}
$$


Taking the upper limit in (77) and using (75) and Lemma 1.1, we get

$$
\begin{aligned}
\psi\left(\int_{0}^{\epsilon} \varphi(t) d t\right)= & \lim _{k \rightarrow \infty} \sup \psi\left(\int_{0}^{d\left(f^{m(k)+1} x f^{n(k)+2} x\right)} \varphi(t) d t\right) \\
\leq & \lim _{k \rightarrow \infty} \sup \alpha\left(f^{m(k)} x, f^{n(k)+1} x\right) \psi\left(\int_{0}^{d\left(f^{m(k)+1} x f^{n(k)+2} x\right)} \varphi(t) d t\right) \\
\leq & \lim _{k \rightarrow \infty} \sup \beta\left(M\left(f^{m(k)} x, f^{n(k)+1} x\right)\right) \phi\left(\int_{0}^{M\left(f^{m(k)} x_{f} f^{n(k)+1} x\right)} \varphi(t) d t\right) \\
& +L \lim _{k \rightarrow \infty} \sup \psi\left(\int_{0}^{O\left(f^{m(k)} x, f^{n(k)+1}\right)} \varphi(t) d t\right) \\
\leq & \lim _{k \rightarrow \infty} \sup \beta\left(M\left(f^{m(k)} x, f^{n(k)+1} x\right)\right) \psi\left(\int_{0}^{M\left(f^{m(k)} x_{f}^{n(k)+1} x\right)} \varphi(t) d t\right) \\
& +L \lim _{k \rightarrow \infty} \sup \psi\left(\int_{0}^{O\left(f^{m(k)} x_{f} f^{n(k)+1}\right)} \varphi(t) d t\right) \\
< & \psi\left(\int_{0}^{\epsilon} \varphi(t) d t\right),
\end{aligned}
$$

which is impossible. Thus $\left\{f^{n} x\right\}_{n \in \mathbb{N}}$ is a Cauchy sequence. Now, since $(X, d)$ is complete, there exists a point $a \in X$ such that $\lim _{n \rightarrow \infty} f^{n} x=a$. From the continuity of $f$, it follows that $x_{n}=f x_{n+1} \rightarrow f u$ as $n \rightarrow+\infty$. From the uniqueness of limits, we get $a=f a$, that is, $u$ is a fixed point of $f$. This completes the proof.

\section{Conclusion}

In this paper, we handle contractive mappings of integral type in a more general frame via $\alpha$-admissible mappings. More precisely, we examine the contractive mapping of integral type given in [11] by using $\alpha$-admissible mappings. Very recently, some new contractive mappings of integral type were introduced in [12] and [13]. We assert that our techniques are also valid to extent the results of [12] and [13] in the frame of $\alpha$-admissible mappings.

\section{Competing interests}

The authors declare that they have no competing interests.

\section{Authors' contributions}

All authors contributed equally and significantly in writing this article. All authors read and approved the final manuscript.

\section{Author details}

${ }^{1}$ Nonlinear Analysis and Applied Mathematics Research Group (NAAM), King Abdulaziz University, Jeddah, Saudi Arabia. ${ }^{2}$ Department of Mathematics, Atilim University, Incek, Ankara, 06836, Turkey. ${ }^{3}$ School of Mathematics, Statistics and Applied Mathematics, National University of Ireland, Galway, Ireland. ${ }^{4}$ School of Mathematics and Computer Applications, Thapar University, Patiala, Punjab 147004, India.

\section{Acknowledgements}

This project was funded by the Deanship of Scientific Research (DSR), King Abdulaziz University, under Grant No. (55-130-35-HiCi). The authors, therefore, acknowledge technical and financial support of KAU.

Received: 30 May 2014 Accepted: 25 September 2014 Published: 14 Oct 2014

\section{References}

1. Branciari, A: A fixed point theorem for mappings satisfying a general contractive condition of integral type. Int. J. Math. Math. Sci. 29(9), 531-536 (2002)

2. Abbas, M, Rhoades, BE: Common fixed point theorems for hybrid pairs of occasionally weakly compatible mappings satisfying generalized contractive condition of integral type. Fixed Point Theory Appl. 2007, Article ID 54101 (2007) 
3. Altun, I, Türkoglu, D, Rhoades, BE: Fixed points of weakly compatible maps satisfying a general contractive condition of integral type. Fixed Point Theory Appl. 2007, Article ID 17301 (2007)

4. Altun, I, Türkoglu, D: Some fixed point theorems for weakly compatible multivalued mappings satisfying some general contractive conditions of integral type. Bull. Iran. Math. Soc. 36(1), 55-67 (2010)

5. Djoudi, A, Aliouche, A: Common fixed point theorems of Gregus type for weakly compatible mappings satisfying contractive conditions of integral type. J. Math. Anal. Appl. 329(1), 31-45 (2007)

6. Rhoades, BE: Two fixed-point theorems for mappings satisfying a general contractive condition of integral type. Int J. Math. Math. Sci. 63, 4007-4013 (2003)

7. Sintunavarat, W, Kumam, P: Gregus type fixed points for a tangential multivalued mappings satisfying contractive conditions of integral type. J. Inequal. Appl. 2011, Article ID 3 (2011)

8. Suzuki, T: Meir-Keeler contractions of integral type are still Meir-Keeler contractions. Int. J. Appl. Math. Sci. 2007, Article ID 39281 (2007)

9. Vetro, C: On Branciari's theorem for weakly compatible mappings. Appl. Math. Lett. 23(6), 700-705 (2010)

10. Vijayaraju, P, Rhoades, BE, Mohanraj, R: A fixed point theorem for a pair of maps satisfying a general contractive condition of integral type. Int. J. Math. Math. Sci. 15, 2359-2364 (2005)

11. Liu, Z, Li, J, Kang, SM: Fixed point theorems of contractive mappings of integral type. Fixed Point Theory Appl. 2013, Article ID 300 (2013)

12. Liu, Z, Wu, H, Ume, JS, Kang, SM: Some fixed point theorems for mappings satisfying contractive conditions of integral type. Fixed Point Theory Appl. 2014, Article ID 69 (2014)

13. Liu, Z, Han, Y, Kang, SM, Ume, JS: Common fixed point theorems for weakly compatible mappings satisfying contractive conditions of integral type. Fixed Point Theory Appl. 2014, Article ID 132 (2014)

14. Samet, B, Vetro, C, Vetro, P: Fixed point theorem for $\alpha-\psi$ contractive type mappings. Nonlinear Anal., Theory Methods Appl. 75, 2154-2165 (2012)

15. Karapınar, E: Discussion on $(\alpha, \psi)$ contractions on generalized metric spaces. Abstr. Appl. Anal. 2014, Article ID $962784(2014)$

16. Karapınar, E, Samet, B: Generalized $\alpha$ - $\psi$-contractive type mappings and related fixed point theorems with applications. Abstr. Appl. Anal. 2012, Article ID 793486 (2012)

17. Aydi, H, Karapınar, E, Samet, B: Fixed points for generalized $(\alpha, \psi)$-contractions on generalized metric spaces. J. Inequal. Appl. 2014, Article ID 229 (2014)

18. Asl, JH, Rezapour, S, Shahzad, N: On fixed points of $\alpha-\psi$-contractive multifunctions. Fixed Point Theory Appl. 2012, Article ID 212 (2012). doi:10.1186/1687-1812-2012-212

19. Mohammadi, B, Rezapour, S, Shahzad, N: Some results on fixed points of $\alpha$ - $\psi$-Ćirić generalized multifunctions. Fixed Point Theory Appl. 2013, Article ID 24 (2013). doi:10.1186/1687-1812-2013-24

20. Ali, MU, Kamran, T: On $\left(\alpha^{*}, \psi\right)$-contractive multi-valued mappings. Fixed Point Theory Appl. 2013, Article ID 137 (2013). doi:10.1186/1687-1812-2013-137

21. Ali, MU, Kamran, T, Sintunavarat, W, Katchang, P: Mizoguchi-Takahashi's fixed point theorem with $\alpha, \eta$ functions Abstr. Appl. Anal. 2013, Article ID 418798 (2013)

22. Abdeljawad, T: Meir-Keeler $\alpha$-contractive fixed and common fixed point theorems. Fixed Point Theory Appl. 2013, Article ID 19 (2013). doi:10.1186/1687-1812-2013-19

23. Karapınar, E, Kumam, P, Salimi, P: On $\alpha$ - $\psi$-Meir-Keeler contractive mappings. Fixed Point Theory Appl. 2013, Article ID 94 (2013). doi:10.1186/1687-1812-2013-94

24. Chen, CM, Karapınar, E: Fixed point results for the $\alpha$-Meir-Keeler contraction on partial Hausdorff metric spaces. J. Inequal. Appl. 2013, Article ID 410 (2013). doi:10.1186/1029-242X-2013-410

25. Salimi, P, Latif, A, Hussain, N: Modified $\alpha$ - $\psi$-contractive mappings with applications. Fixed Point Theory Appl. 2013 Article ID 151 (2013). doi:10.1186/1687-1812-2013-151

26. Hussain, N, Salimi, P, Latif, A: Fixed point results for single and set-valued $\alpha-\eta-\psi$-contractive mappings. Fixed Point Theory Appl. 2013, Article ID 212 (2013). doi:10.1186/1687-1812-2013-212

27. Mohammadi, B, Rezapour, S: On modified $\alpha-\varphi$-contractions. J. Adv. Math. Stud. 6, 162-166 (2013)

28. Berzig, M, Karapınar, E: Note on 'Modified $\alpha$ - $\psi$-contractive mappings with application'. Thai J. Math. 2014, Article ID 4 (2014)

29. Ali, MU, Kamran, T, Karapınar, E: $(\alpha, \psi, \xi)$-Contractive multi-valued mappings. Fixed Point Theory Appl. 2014, Article ID 7 (2014). doi:10.1186/1687-1812-2014-7

30. Ali, MU, Kamran, T, Karapınar, E: A new approach to $(\alpha, \psi)$-contractive nonself multivalued mappings. J. Inequal. Appl. 2014, Article ID 71 (2014). doi:10.1186/1029-242X-2014-71

31. Ali, MU, Kamran, T, Kiran, Q: Fixed point theorem for $(\alpha, \psi, \phi)$-contractive mappings on spaces with two metrics. J. Adv. Math. Stud. 7, 8-11 (2014)

10.1186/1687-1812-2014-213

Cite this article as: Alsulami et al.: Fixed points of generalized contractive mappings of integral type. Fixed Point Theory and Applications 2014, 2014:213 